\title{
KANT E O IDEALISMO: A RELAÇÃO DO EU PENSO COM A FUNDAÇÃO DE TODA A CIÊNCIA NO PENSAMENTO ALEMÃO
}

\section{KANT AND IDEALISM: THE RELATIONSHIP OF THE EU I THINK WITH THE FOUNDATION OF ALL SCIENCE IN GERMAN THOUGHT}

\author{
Lindomar Rocha Mota*
}

\begin{abstract}
RESUMO
Este artigo descreve a evolução da consciência no pensamento moderno alemão. A evolução do problema sobre a fundação da ciência é discutida com base na descoberta de Descartes e seu desenvolvimento na filosofia de Kant. A retomada do princípio de certeza pelos Idealistas até o espírito absoluto de Hegel constitui o centro da investigação, que se conclui com a superação total do mundo objetivo. As polêmicas que surgiram depois que Kant limitou a razão humana é o centro dos debates para o mais importante grupo de filósofos modernos. Fichte, que começou respondendo aos ataques provenientes do ceticismo, aboliu partes desses limites e reinaugurou o pensar ilimitado. Schelling, que nunca se sentiu à vontade com a limitação "preguiçosa" do intelecto, lançou para frente e para o alto as capacidades do saber humano. Por fim, Hegel, concluindo esse caminho, demonstrará que nenhuma ciência se funda fora do pensar humano, e buscará na metafísica mais alta de Aristóteles a referência para o pensamento que pensa a si mesmo.
\end{abstract}

PALAVRAS-CHAVE: Cogito. Ciência. Fundamento. Ideia. Consciência.

\begin{abstract}
This article describes the evolution of consciousness in modern German thought. The evolution of the problem about the foundation of science is discussed on the basis of the discovery of Descartes and its development in Kant's philosophy. The resumption of the principle of certainty by the Idealists to the absolute spirit of Hegel constitutes the center of the investigation, which concludes with the total overcoming of the objective world. The polemics that arose after Kant limited human reason is the center of the debates for the most important group of modern philosophers. Fichte, who began by responding to attacks from skepticism, abolished parts of these limits and reopened unlimited thinking. Schelling, who was never at ease with the "lazy" limitation of the intellect, launched the capacities of human knowledge forward and upward. Finally, Hegel, concluding this path, will demonstrate that no science is founded outside of human thinking, and will seek in Aristotle's highest metaphysics the reference to thought that thinks to itself.
\end{abstract}

KEYWORDS: Cogito. Science. Foundation. Idea. Awareness.

\footnotetext{
* Doutor em filosofia moderna pela Universidade Gregoriana. Professor da PUC Minas e FAC. E-mail: lrocht@yahoo.com.br.
} 


\section{INTRODUÇÃO}

No século XVIII o Cogito ergo sum cartesiano já se instaurara na filosofia e na ciência. O Eu penso tomado como fundamento de toda certeza marcou o início da filosofia moderna e ocupou uma parte significativa dos tratados anteriores ao pensamento de Kant e ao advento do Idealismo, tornando-se, em certo modo, a principal questão dos modernos.

Kant, como sabemos, enveredou por esse caminho depois de 1770, quando organizou, ao redor de suas três Críticas, uma ponderação sobre o alcance e os limites do conhecimento humano.

A ideia de começar a investigação do conhecimento a partir do entendimento e da intuição gerou a expectativa de que Kant estivesse conciliando o racionalismo e o empirismo, correntes preponderantes à época. Entretanto, a questão se revela mais complicada que a simples construção de uma síntese, pois, além desses dois princípios, Kant indicou uma raiz comum, o eu penso (Ich denke), que faz a ligação entre o entendimento e a intuição, e constatou que ela é desconhecida para nós.

Kant segue, todavia, com relação ao eu penso, uma trajetória diferente daquela cartesiana e bem mais próxima de seu desenvolvimento na tradição alemã de Leibniz e Wolff, na qual o eu penso foi recebido como princípio da consciência, sem nenhuma afinidade com a fundamentação de certeza.

Kant foi ainda mais longe e duvidou inclusive da capacidade do cogito de fundar a própria existência, como pretendido em Descartes.

A retomada do eu penso no pensamento de Kant está presente na Crítica da razão pura, nas edições de 1781 = a e 1787 = b, e é extremamente ambígua, e expressa como segue:

Chegamos agora a um conceito que não foi indicado anteriormente na lista dos conceitos transcendentais, mas que, todavia, tem que lhe ser acrescentado, sem que no entanto se altere, no mínimo que seja, essa tábua ou se declare incompleta. Trata-se do conceito, ou se prefere, do juízo: eu penso. (KANT, 1994, a341; b399).

Até esse ponto há uma coincidência entre as duas edições. Entretanto, foi apenas na segunda edição, de 1787, que Kant se confrontou com a tradição fundacionista advinda de Descartes. Ao discutir a ideia de simplicidade Kant assevera o seguinte: "A proposição: eu sou simples deve considerar-se expressão imediata da apercepção; igualmente o pretenso raciocínio cartesiano, cogito ergo sum, é, de facto, tautológico, pois o cogito (sum cogitans) exprime imediatamente a realidade.”(KANT, 1994, b354-355). 
Artigo: Kant e o idealismo: a relação do eu penso com a fundação de toda a ciência no pensamento alemão

Kant parece considerar que o eu penso é semelhante ao princípio de identidade aristotélico, indemonstrável por si mesmo, e uma condição formal para a própria ciência. Em ordem lógica ele é o primeiro princípio; se fosse demonstrado deixaria de sê-lo e cederia o lugar a outro, caindo num regresso infinito. Creio ser possível fazer essa observação, haja vista que Kant pretende dialogar, em sua primeira Crítica, com a lógica de Aristóteles, seja imersa na metafísica ou na própria doutrina das categorias. Esse parecer pode ser retirado da própria continuação de (a355) que permanece afirmando: "Eu sou simples não significa, porém, senão que esta representação $e u$ não contém em si a mínima diversidade e que é uma unidade absoluta (embora puramente lógica)".

Nesse contexto o $E u$ (Ich) surge no pensamento Crítico como o princípio de identidade, uma raiz desconhecida que liga o entendimento à intuição sem, contudo, garantir nenhuma certeza ou alterar a tábua das categorias, essas sim, início da ciência.

Esse $E u$, que nem mesmo foi definido se era um "conceito" ou um "juízo”, é bastante escasso no pensamento de Kant. Por ser impossível de representação, permanece como uma raiz desconhecida, cuja tentativa de apreensão resultaria em dogmatismo, algo a ser evitado.

Essa perspectiva secundária da filosofia Crítica foi o que propriamente interessou aos idealistas alemães, especialmente Fichte e Hegel, que a tomaram como ponto de partida e princípio incondicionado ou absoluto do conhecimento humano.

Ela ressurge em todo o contexto de desenvolvimento da filosofia que vai da admiração de Fichte, com a publicação da Crítica a toda revelação e de sua recensão aos escritos de Schulze $^{1}$, à instauração do fundamento de toda a ciência, passando pela elaboração da evidência do $E u$ como algo dado à intuição, até a remoção completa da proibição que Kant fez à intuição intelectual.

Na mesma linha, Hegel começou pelo exame da filosofia de Kant, mas diferentemente, e já influenciado pelo próprio Fichte, declarou-se contra a limitação do conhecimento desde o início, chamando em seu auxílio, no primeiro momento, o pensamento de Spinoza e Jacob ${ }^{2}$, mais tarde Hegel continuará fiel a esse princípio, podendo se justificar na Enciclopédia.

\footnotetext{
${ }^{1}$ Gottlob Ernst Schulze é um cético moderno que reagiu à possível vitória de Kant sobre Hume. Schulze escreveu quando o Criticismo já estava consolidado e foi combatido principalmente por Fichte. A sua obra mais conhecida, Aenesidemus, reporta-se a um cético grego do primeiro século a.C que elaborou proposições em defesa do ceticismo. De igual modo, Schulze também se esforçará para defender o ceticismo presente, inclusive no criticismo de Kant.

${ }^{2}$ Principalmente no texto Fé e saber (Gluben und Wissen) de 1802 e visava combater as ambiguidades do criticismo kantiano.
} 
Em todo caso, o problema do $E u$ ou da raiz desconhecida que Kant deixou suspensa, por falta de uma intuição adequada para evidenciá-la, tornou-se a principal questão para Idealismo alemão.

Há duas justificativas pelas quais Fichte e Hegel, e neste aspecto também Schelling, não puderam renunciar a ela: a primeira é que essa raiz constitui o fundamento e a condição de toda ciência; e, a segunda, ela é o que existe de mais interessante para se pensar. Renunciar, portanto, a esta problemática seria como renunciar à própria filosofia, como bem se expressou Schelling: "Perdemos esse princípio interior quando perdemos a intuição intelectual do mundo, que surge pela unificação instantânea dos dois princípios conflitantes em nós, e que está perdida desde o momento em que não pode haver em nós nem luta nem unificação.” (SCHELLING, 1980, p. 6).

É possível, portanto, dentro da história moderna da filosofia, ligar, ainda que por caminhos tortos, o nascimento e o desenvolvimento do Idealismo alemão ao pensamento de Kant, e particularmente a sua primeira Crítica, ainda que a contragosto do autor.

\section{DO EU À AUTOCONSCIÊNCIA}

O problema do eu como autoconsciência ${ }^{3}$ se apresenta já na origem da filosofia moderna, principalmente com Descartes, com o qual Kant está de acordo na constatação de que é a consciência a organizar uma cadeia estável de deduções que funda o inteiro campo do saber.

Kant aceita ainda, como em Descartes, a existência de uma característica que não pode ser explicada pela experiência, pelo fato de ser posta como fundamento da unidade dessa mesma experiência, o princípio de identidade que liga todas elas em uma única subjetividade. Essa é uma unidade que não pode derivar do empírico, e que, por isso, é uma constatação transcendental, como dito a seguir: "O eu penso deve poder acompanhar todas as minhas representações; se assim não fosse, algo se representaria em mim, que não poderia de modo algum, ser pensado, que o mesmo é dizer que a representação seria impossível ou pelo menos nada seria para mim”. (KANT, 1994, b132).

\footnotetext{
${ }^{3}$ Embora o termo tenha aparecido efetivamente com Kant, em que a autoconsciência (Selbstbewusstsein) será apenas uma organizadora do material recebido através da sensibilidade, ela se tornará cada vez mais importante no Idealismo. Já a partir de Fichte ela será um eu infinito, capaz de engendrar os seus próprios objetos.
} 
Artigo: Kant e o idealismo: a relação do eu penso com a fundação de toda a ciência no pensamento alemão

Parecia que a partir desse enunciado a Crítica deveria começar com a busca dessa unidade transcendental e pré-condição inicial de possibilidade do universo empírico. Entretanto, desde Descartes, o saber, em sua totalidade, já se mostrava problemático. Quando é analisado em sua completeza ele acaba entrando em um círculo, do qual o sujeito não adquire consciência de que o seu saber é o saber que estava procurando, ou mesmo um saber válido que corresponda aos objetos no mundo. A qualidade essencial para fugir desse círculo é a descoberta do ato originário, primitivo, que não precise de demonstração, evidente por si mesmo, como o eu penso. Esse cogito aparece como a primeira evidência da realidade e princípio de autoconsciência.

Permanece em Kant, a respeito da constatação de Descartes ${ }^{4}$, que essa realidade é a única possível para se iniciar a metafísica como ciência, mas é outro tanto certo que esta intuição não pode se dar no mundo da experiência, e que, portanto, será apenas uma constatação transcendental, como possibilidade de todas as experiências que ocorrem no espaço e no tempo, sendo que ela mesma não se dá como experiência e permanece no limite dos postulados.

Das conclusões de Descartes, que evoluíram em Kant, derivam duas constatações fundamentais:

- a inacessibilidade do eu a si mesmo, pois funciona tão somente como postulado da ciência e;

- a impensabilidade do absoluto, que permanece fora, até mesmo do campo dos postulados, dando ao conhecimento uma restrição que será permanente e metódica para o desenvolvimento da Crítica.

Considerando o conhecimento dependente da sensibilidade e do entendimento, Kant deduz que eles se encontram em um lugar comum, um ponto único, tal como a psique de Aristóteles, que organizava todas as outras faculdades.

\footnotetext{
${ }^{4}$ As meditações de Descartes, particularmente a terceira, estabelece um primeiro princípio da ciência, o cogito. O cogito é a evidência fundamental de toda demonstração futura. Contudo, Descartes não evita de recorrer a Deus para sustentar a sua validade. Daí nasce a possibilidade de se pensar o infinito, ausente na Crítica kantiana. Deus é a substância perfeita que garante a validade do primeiro principio: "Itaque sola restat Idea Dei, in qua considerandum est na aliquid sit quod a me ipso non potuerit proficisci [...] nec putare debeo me non percepire infinitum per veram ideam, sed tantùm per negationem finit. Nec dici potest hanc forte ideam Dei mataerialiter falsam esse" (DESCARTES, 1996, p. 45-46). Deus é a ideia clara e distinta, da qual não se pode duvidar. O Eu penso (Ich denke) kantiano, entretanto, não é a evidência da realidade, e, mesmo se assim o fosse, estaria muito mais perto de Fichte que de Descartes; o Ich denke de Kant é apenas a condição necessária para ligar a multiplicidade empírica em uma representação, sem, contudo, estabelecer a realidade da ideia, que aflorará por meio de uma crítica.
} 
A raiz desconhecida deve permanecer como tal. Ela não é passível de nenhuma intuição. Até poderia ser percebida, mas nunca intuída. A causa disso é que a intuição humana é sensível, e, nesse caso, seria necessária uma intuição intelectual para operar esse movimento.

Kant, entretanto, fecha as portas à intuição intelectual para o humano. Ela só seria possível se considerássemos, ao menos uma vez, a possibilidade de um entendimento criador. Nesse caso, o objeto seria constituído a partir do próprio intelecto, semelhante ao ato divino. Essa impossibilidade encerra, portanto, o intelecto no mundo sensível e estabelece a sua referência a objetos sensíveis, como ele mesmo explica ao afirmar que "sem sensibilidade, nenhum objeto nos seria dado" (KANT, 1994, b75).

Kant é reticente ao fazer afirmações sobre a raiz desconhecida que une intuição e entendimento. Talvez as duas procedam de um lugar comum, diz ele; mas, em todo caso, ela não é objeto de ciência nem é o fundamento de qualquer ciência. Ele está inclinado a aceitar como condição da ciência um certo modo de procedimento crítico que possui, entre outras funções, a de limitar o interesse por questões desse tipo.

A evolução que ocorre no pensamento de Kant a respeito desse princípio incondicionado gerou inúmeros debates no âmbito da filosofia moderna, e se juntou a outros tantos objetos de que, segundo Kant, a razão não consegue se livrar, pois subsistem como uma tendência constante.

Kant confere vários títulos ao princípio incondicionado no Cânone da razão pura e, quase na conclusão da Crítica da razão pura, por exemplo, o chama de fonte positiva, mas unifica essas fontes dizendo que são todos princípios além do limite da experiência.

Assim, foi estabelecida, de uma vez por todas, a demarcação do conhecimento humano. Kant alerta que não há nesse procedimento nenhum desmerecimento nem ceticismo ao modo do conhecer crítico. É a elementar constatação de um limite natural que dispõe os objetos para o entendimento a partir da única intuição que ele possui, a sensível.

Não sabemos, de fato, como o conhecimento procederia se formulado a partir de intuições intelectuais; não se pode nem mesmo desconsiderá-lo, pois parece ser mais apropriado ao intelecto divino que ao nosso.

Apesar das observações, a busca pelo incondicionado continuou ainda no círculo kantiano, quando Fichte pertencia a ele. 
Artigo: Kant e o idealismo: a relação do eu penso com a fundação de toda a ciência no pensamento alemão

No âmbito das disputas céticas envolvendo Schulze - um discípulo de Hume - e o pensamento kantiano, desenvolve-se o caminho de reintegração da intuição intelectual no Idealismo nascente.

Em seu Aenesidemus Schulze demonstra que, seguindo a filosofia de Kant, só sobrava para o conhecimento a representação, e o mundo em si estava perdido. Desse modo, ele não via razões para alguém proclamar a vitória de Kant sobre Hume e o seu ceticismo, pois, no fundo, a filosofia de Kant também era um ceticismo.

Essa disputa é importante, e é com ela que Fichte reintroduz a intuição intelectual na filosofia, mesmo contra as observações de Kant.

\subsection{Criticismo e ceticismo}

As interpretações da Crítica da razão pura assumiram uma proporção muito maior com relação a outras filosofias, e assombrou não apenas os estudantes diletantes, mas também aquela classe mais especializada de professores e catedráticos, ainda imersos no pensamento das escolas ${ }^{5}$. E foram essas tantas interpretações que popularizaram a primeira Crítica kantiana.

As dificuldades que rondaram a interpretação e a tentativa de popularização de uma obra como é a Crítica da razão pura não tardariam a se apresentar no quadro polêmico em que se encontravam as universidades alemãs do tempo, com a forte tendência para o ceticismo que Hume havia impulsionado com sua filosofia ${ }^{6}$.

\footnotetext{
${ }^{5}$ Leon se refere dramaticamente com respeito às interpretações da filosofia de Kant: "Les dogmatitiques combattaient en elle un nouveau scepticisme; les sceptiques étaient tentés d'y voir une restauration du dogmatisme sur les ruines des anciens systèmes; les supernaturalistes admiraient son artifice pour écarter les bases historiques de la religion et pour y substituer sans polemique les fondements d'un naturalisme, les naturalistes dénonçaient un nouvel effort pour faire revivre la philosophie de la croyance, alors chancelante; les matérialistes découvraient dans la Critique une réfutation idéaliste de la réalitè de la matière; les spritualistes étaient indignes de la limitation imposée à la connaissance du réel, au nom de l'expérience; les éclectiques parlaient du Kantisme comme d'une nouvelle secte, plus intolérant que les autres, de la philosophie prétendue populaire, et ridiculisaient cette rénovation de la scolastique et dês subtilités de l'École, dans le siècle des lumières et du bom sens" (LEON, 1922, p. 219-220)

${ }^{\mathrm{O}}$ empirismo de Hume superou o realismo lógico que se tinha desenvolvido no período medieval. A universalidade dos conceitos, em verdade, tinha deixado de ser uma demonstração válida filosoficamente, passando a subsistir apenas como hábito. Os princípios da universalidade são conduzidos sobre o esquema de causa e efeito, mas nem mesmo aqui essa é uma operação que se apresenta sempre a posteriori, e logo na experiência. As operações do intelecto são colocadas em dúvida nessa constatação cética (HUME, 1998, ses. IV). Mesmo Hegel, quase na conclusão do Idealismo, manterá essa polêmica ao defender que Kant não superou o ceticismo. Diz ele "A filosofia crítica tem em comum com o empirismo admitir a experiência como único terreno do conhecimento; que aliás ela não reconhece por verdade mas somente por conhecimento de fenômenos" (HEGEL, 1995, I§40).
} 
Reinhold ${ }^{7}$, um intérprete que teve seu trabalho apreciado pelo próprio Kant, tentou, pela primeira vez, introduzir a filosofia crítica em um ambiente mais amplo através de uma popularização. Entretanto, o rigor e a sensibilidade com os quais Kant tinha operado as distinções, navegando entre o fenômeno e o noumeno, perderam-se nessa nova simplificação. Ao reduzir todo o problema da Crítica ao dualismo entre matéria e forma, jogou-se a coisa em si para o campo das impressões, procedimento que abriu caminho para reintrodução do ceticismo, que até então não havia digerido completamente o método da Crítica (REINHOLD, 1789, p. 560-564).

Reinhold impôs à filosofia crítica um esquema representacionista, a partir do qual Schulze retorna ao filão cético e analisa a filosofia crítica através dessa ótica, e denuncia o engano de que o criticismo houvesse superado o ceticismo no seu quadro geral. O que de real o criticismo fez, segundo Schulze, foi limitar a coisa em si no campo das impressões. A negação do ceticismo nesse novo contexto aparece apenas como uma atitude dogmática da parte de Kant. E mais, o criticismo é na verdade uma espécie de ceticismo ${ }^{8}$.

Schulze questiona, com muita consequência, a possibilidade de abertura dessa representação ao mundo objetivo. Porque, segundo a conclusão de Reinhold, a representação permanece uma realidade factual. Mas se a representação permanece uma coisa em si (das Ding an sich), fora do $e u$, mas ao mesmo tempo dentro ${ }^{9}$, já que não existe a separação entre fenômeno e noumeno, torna-se o terreno propício para o ceticismo, porquanto não é possível sair da representação para verificar o estado da coisa, e cada vez que se verificasse uma atividade com essa pretensão seria apenas uma multiplicação da própria representação, gerando, nesse caso, um círculo infinito. Por fim, o próprio eu, que repousa nessa subjetividade, no seu próprio ato de procurar-se, formaria a cada vez uma nova representação de si mesmo (SCHULZE, 1911, p.160).

\footnotetext{
7 Karl Leonard Reinhold, embora desconhecido, é um filósofo fundamental para o desenvolvimento do Idealismo alemão. Sua importância foi tal que Market confessa: "há que se ter presente que, de facto, a partir de 1789, todo diálogo com o pensamento kantiano se faz através da versão que dele oferece Karl Reinhold" (MARKET, 1992, p.158). Reinhold escreveu oito cartas, depois reunidas e publicadas em conjunto, que foram muito apreciadas por Kant, por servir de introdução à Crítica. Entretanto, a simplificação operada por ele aumentou bastante os ataques ao kantismo e o número dos adversários.

${ }^{8}$ Schulze, retornando ao filão cético, analisa a filosofia crítica através da ótica de Reinhold, e vê nela uma impossibilidade de superação do ceticismo no seu quadro geral, uma vez que Reinhold tinha reduzido a coisa em si ao campo das impressões. A negação do ceticismo nesse novo contexto aparece apenas como uma atitude dogmática da parte de Kant (SCHULZE, 1911, p. 4-10).

Tilliette se expressa com perfeita clareza a respeito da impostação de Reinhold: “A vrai dire Reinhold n'a pas touché à la chose, mais il a délié le mot de la chose et préparé ainsi la voie à la rupture hardie de Fichte. Le maître-mot de Reinhold est la représentation, avec laquelle il croit pouvoir unifier toute la théorie de la connaissance, scindée et subdivisée chez Kant.” (TILLIETTE, 1995, p.39).
} 
Artigo: Kant e o idealismo: a relação do eu penso com a fundação de toda a ciência no pensamento alemão

A estrada interpretativa de Reinhold abriu uma margem analítica à filosofia crítica, segundo a qual Schulze passa a considerar que a representação não era apenas uma faculdade cognoscitiva, mas era, em fim de contas, uma coisa que se interpunha entre o eu e o mundo, gerando uma grade ilusória a respeito da realidade, e confirmando, por outro lado, o ceticismo.

Ao rejeitar a complexidade da Crítica, Reinhold introduziu uma segunda separação entre sujeito e objeto, que passam a coexistir em uma morosidade constante por meio de duas cópias de conceitos. De uma parte, a dinâmica entre a forma e a matéria é o que estabelece a relação entre o sujeito, fonte da forma e da matéria, inerência dos objetos no mundo, unidos pela consciência e permanece uma operação do sujeito pensante; por outro lado, o fenômeno e a coisa em si se relacionam apenas na consciência que, por sua vez, segundo o entendimento de Reinhold, é contemporaneamente diferente do representante e do representado (TILLIETTE, 1995, p. 40-43).

Com essa trajetória Reinhold pensava ter encontrado a solução definitiva entre o problema do fenômeno, condição real do conhecimento, e o noumeno, realidade mundana da qual não se pode adquirir conhecimento. Mas foi essa referência à representação da consciência, como algo sem ralação com o sujeito nem com o objeto, que atiçaria os protestos de Schulze. Para ele o kantismo seria uma espécie de intuição indemonstrável, que quando expelida pela própria Crítica não encontra mais que um círculo infinito, uma representação da representação, incapaz de alcançar um conhecimento certo. Em outras palavras, Schulze vê na filosofia kantiana, interpretada por Reinhold, uma prova de sua tendência cética que ainda ecoava sobre a teoria do hábito de Hume (SCHULZE, 1911, p. 133-142). Algo que o próprio Kant combateu desde o início em sua Crítica da razão pura ${ }^{10}$.

É sobre essas condições que começam a se difundir as polêmicas em torno da filosofia Crítica, polêmicas essas que se estenderão através da elaboração de muitos sistemas de pensamentos, e, em particular, fundará todo o idealismo alemão do século XIX, gerando alguns dos nomes mais ilustres da filosofia no Ocidente, a exemplo de Fichte, Schelling e Hegel, que, em diversas maneiras, estão em contato direto com o problema da fundação da ciência.

\footnotetext{
${ }^{10}$ O primeiro passo da segunda edição da Crítica da razão pura, começa por uma correção profunda à filosofia agnóstico-cética de Hume: "Não resta dúvida de que todo o nosso conhecimento começa com a experiência ... se, porém, todo o conhecimento se inicia com a experiência, isso não prova que todo ele deriva da experiência." (KANT, 1994, b1). A porta se abre de novo para uma concepção universal do conhecimento, uma vez que seu suporte exclusivo não se encontra apenas na experiência, mas se origina fora desta. A descoberta dessa possibilidade constitui a preocupação principal daquela obra.
} 


\subsection{Evolução da questão}

O ponto central dessa controvérsia consiste no fato de que Kant realmente tinha encontrado um ponto válido para a fundação da ciência, mas foi incapaz de tirar as consequências máximas da descoberta.

A questão se propagou na direção deste único problema: de como seja possível ao nosso conhecimento se referir com exclusividade à representação e, mesmo assim, atingir a certeza? E mais, que essa certeza não seja uma mera subjetividade ou ceticismo.

Para essa problemática Schulze não retornou propriamente ao pensamento kantiano, no qual encontraria boa parte das respostas, mas sim à interpretação de Reinhold ${ }^{11}$. O idealismo subsequente segue uma linha paralela, buscando, não como Schulze, abrir a porta para o ceticismo, mas evitá-lo, transportando a realidade para a subjetividade ${ }^{12}$.

O idealismo que surge com fundamento na filosofia crítica, marcado pelo caráter romântico, não se nega a restituir à razão o poder constitutivo da realidade, e, como tal, garantir a realidade extramundana. Fichte é o consequente sucessor de Kant na refundação da originalidade do eu. O eu puro marca o retorno à filosofia como saber sui generis, segundo a qual o sujeito está imediatamente em relação consigo mesmo, como a primeira possibilidade da experiência e fonte de certeza. Essa experiência em Fichte é uma intuição imediata, que deve fundar um sistema completo do saber.

O que se encontrava em Kant, mas apenas como um postulado, passa a constituir na filosofia um princípio dominante, capaz de transportar a realidade do mundo externo para dentro do sujeito pensante, algo adequado para superar a contradição entre o sujeito e o objeto.

A possibilidade de uma intuição intelectual, que Kant rejeitou obstinadamente ${ }^{13}$, retorna triunfante no pensamento de Fichte, ao menos ao que concerne a fundação da filosofia

\footnotetext{
${ }^{11}$ Marechal resume bem a questão: "L'auteur en était, on le sut plus tard, un jeune Dozent de philosophie, G.E. Schulze, que l'on surnomma, pour le distinguer de tant d'homonymes, Énésidème-Schulze. Son pamphlet, où les remarques pénétrantes ne manquent pas, visent Kant à travers Rainhold, et d'ailleurs directement aussi" (MARECHAL, 1947, p.212).

${ }^{2}$ Xavier Tilliette, no livro L'Intuition intellectuelle de Kant à Hegel, (1995), na página 46, especificamente e, em geral no todo da obra, demonstra o progresso dessa polêmica no início do idealismo alemão.

Kant diz expressamente: "Sejam quais forem o modo e os meios pelos quais um conhecimento se possa referir a objetos, é pela intuição que se relaciona imediatamente com estes e ela é o fim para o qual tende, como meio, todo o pensamento. Esta intuição, porém, apenas se verifica quando o objeto nos for dado; o que por sua vez só é possível, [pelo menos para nós homens,] se o objeto afetar o espírito de certa maneira" (KANT, b31). Retorna então a impossibilidade de uma intuição intelectual, com a qual Fichte parece começar sua ciência. Conferir rejeição kantiana à intuição intelectual no excelente texto de Xavier Tilliette, (1995, p. 47-52).
} 
Artigo: Kant e o idealismo: a relação do eu penso com a fundação de toda a ciência no pensamento alemão

como ciência. Mas, tratando-se do problema kantiano surgido das interpretações, devemos nos perguntar como adentrou em Fichte a possibilidade de um eu puro e absoluto?

Fichte abre o discurso fundamental de sua doutrina da ciência buscando um primeiro princípio simplesmente incondicionado. Diz ele: “Temos que procurar princípio absolutamente primeiro, puro e absolutamente incondicionado, de todo o saber humano. Esse princípio deve ser absolutamente primeiro, não se deixa provar nem determinar" (FICHTE, 1988, p.44). A existência do princípio incondicionado fichtiano quer representar o fundamento último da liberdade do eu que tinha sido posto por Kant, como um relacionamento consigo mesmo. $\mathrm{O}$ fio da polêmica é o ceticismo que Schulze tinha atribuído à filosofia crítica.

O fundamento da ciência é um sujeito transcendental, que até agora não teve a sua unidade demonstrada na experiência. Fichte quer acertar as contas com essa transcendentalidade, começando o processo de suas deduções com uma experiência, que para ele constitui a exceção e a possibilidade de uma intuição intelectual ${ }^{14}$. O eu penso (ich denke) elabora a condição formal da experiência, mas experiência em Fichte é entendida como conhecimento precedido por um juízo e se apresenta como uma síntese a priori. A apercepção é, nesse caso, a autoconsciência que une a experiência transcendental conjugada analiticamente no juízo, como representação que constitui o objeto pensável.

O pensável primitivo para Fichte é a pura indeterminação; vazio total, que se determina com o comparecimento do $e u$ em sua primeira forma, como um fato. Esse primeiro $e u$, puro e indeterminado, apresenta-se diversamente daquele da representação, e do qual Kant tinha partido na elaboração completa de sua Crítica (FICHTE, 1988, p.44).

Assim, começa a primeira tentativa de liberar o pensamento kantiano da acusação de ceticismo que tinha entrado no todo da interpretação de Reinhold (FICHTE, 1965, p.10ss), e que Schulze havia identificado com muita precisão. Fichte defende, de modo geral, que o movimento que o eu puro faz, partindo da indeterminação de seu primeiro aparecimento no mundo na direção da determinação, é um esforço contra o outro de si, e estabelece uma simbiose, reduzindo a alteridade ao próprio $e u^{15}$.

14 Para além da confissão implícita de Reinhold, a reintrodução da intuição intelectual na filosofia, ocorreu por obra de Fichte também: "wenn das Ich der intellektuellen Anschauung ist, weil es ist, und ist, was es ist; so ist es insofern sich selbst setzend, schlechthin selbständig, und unabhängig" (FICHTE, 1965, p. 65).

${ }^{5}$ Quando Schulze observa na filosofia crítica a necessidade de um esforço contra o próprio objeto da representação, está aberta a porta do ceticismo. É esse o erro que Fichte não quer incorrer pela segunda vez ao afirmar sobre o princípio incondicionado que "ele deve exprimir aquele estado-de-ação (tathandlung), que não aparece nem pode aparecer entre as determinações empíricas de nossa ciência, mas que, muito pelo contrário, está no fundamento de toda consciência e é o único que a torna possível” (FICHTE, 1988, p. 44 et 
O esforço aparece como a experiência que Kant não tinha individuado no seu sistema, mas que, todavia, já estava implícito. O início da ciência não seria, portanto, uma realidade meramente transcendental, mas uma realidade que na ação de se autopôr no mundo se esforça contra a diferença ou o eu negativo (não eu), como tudo que se diferencia, lutando para superar essa diferença através do esforçar-se contra.

O trabalho de Fichte para definir a natureza do esforço, e de como ele possa ser causa, sem, todavia, ser causa no modo tradicional, é um dos momentos mais altos da filosofia. Envolto nessa complicação está o conceito de liberdade, que para Kant tinha um valor concreto apenas na filosofia moral, mas Fichte quer considerá-lo como o primeiro passo do seu sistema. A causalidade do esforço toca o estado de absoluto do eu, que permanece limitado pelo não $e u$. O ato do $e u$ de se por no mundo não toca diretamente o não eu sem esforçar-se contra o diferente que o limita. Nesse caso, o eu aparece como absoluto e através da possibilidade de esforçar-se, sempre com referimento a si mesmo, porque o esforço é uma causalidade que o seu estado finito exige (FICHTE, 1988, p.154156).

O eu puro, posto imediatamente na origem da ciência, não se perde transcendentalmente e não se restringe ao campo da subjetividade, porque a sua primeira ação é de uma experiência no mundo que se esforça para reduzir os outros objetos a si mesmo, como objetos conhecíveis.

A dedução do primeiro incondicionado como fundamento de toda a ciência, deste modo, deságua no Idealismo, mas conserva, nesse primeiro instante, a pretensão de ser uma continuidade coerente da filosofia crítica.

No pensamento de Fichte e do Idealismo vindouro os limites deixaram de ser um problema, porque já não se trata rigorosamente de estabelecer a possibilidade de relação com o objeto, mas sim, de pensar o necessário do mundo, que equivale a antecipar a própria realidade, como um ato criativo amenizado.

Schelling assume a mesma tarefa de Fichte, retirar os limites do conhecimento interpostos por Kant. É claro o desejo de Schelling de não mais se deixar cair nos limites estabelecidos, especialmente quando afirma: "parece-lhe mais grandioso lutar contra uma potência absoluta e sucumbir lutando, do que garantir-se previamente contra todo perigo, através de um Deus moral” (SCHELLING, 1980, p. 5).

seq.). Esse princípio não é somente uma condição ou representação, mas sim, um fato da consciência, sem o qual não existe o mundo, como está a explicar a própria palavra tathandlung (res facti) um princípio real. Coferir também Fichte (1965, p. 6-7). 
Artigo: Kant e o idealismo: a relação do eu penso com a fundação de toda a ciência no pensamento alemão

Nota-se nessa proposição a influência crescente de Fichte, pois as observações preliminares remetem à mesma polêmica com Schulze, na qual Schelling parece indicar que a diferença fundamental entre o dogmatismo e o criticismo só se completa se consideramos seus avanços no pensamento de Fichte.

Dessa vez o problema de Schelling encontra-se atrelado menos no que diz respeito ao ceticismo e mais na relação entre o criticismo e o dogmatismo, sendo que o criticismo se refugiou na moralidade para explicar o único fundamento possível, sem, contudo, expandir essas consequências para o inteiro campo da ciência.

A ideia aqui é a de não limitar a fundação da ciência apenas na faculdade do conhecer, um método usado por Kant, mas sem muita chance de vencer o dogmatismo. O criticismo, segundo Schelling "só tem armas fracas contra o dogmatismo, se fundar seu sistema inteiro apenas na índole de nossa faculdade de conhecer, e não em nosso ser originário" (SCHELLING, 1980, p. 8).

Uma questão é saber especificamente a natureza desse ser originário evocado por Schelling, pois nele parece estar a origem absoluta de toda a ciência. Entretanto, a resposta não é a busca de algo específico, mas sim de um procedimento, cujo modelo pode ser encontrado em Espinosa. A pergunta "por que Espinosa expôs sua filosofia em um sistema $d a$ Ética?" (SCHELLING, 1980, p. 16) desponta como uma indicação norteadora, pois indica os dois princípios tomados para justificar a fundação da ciência: a ideia de sistema e a teoria do esforço que devem se unificar de uma vez por todas.

Os dois princípios se encontram no agir prático, pois "nenhum homem pode convencer-se de um sistema qualquer a não ser, apenas, praticamente, isto é, por ter realizado um dos dois em si mesmo" (SCHELLING, 1980, p. 17). Ao se esforçar em si mesmo o homem produz através da liberdade, e realiza o saber ${ }^{16}$.

Essa solução explica o porquê de Espinosa ter se tornado tão popular na teoria de Schelling e do jovem Hegel. A ética considerada como um discurso sobre o esforço se torna metafísica e ciência dos primeiros princípios, algo que faltava em Kant.

Schelling remove, a partir da junção do teórico e prático em um sistema, todas as limitações interpostas por Kant. Ao afirmar: “é de 'experiências', experiências imediatas, que tem de partir todo o nosso saber" (SCHELLING, 1980, p. 17), ele funda a ciência sobre uma

\footnotetext{
${ }^{16}$ Schelling indica que "temos de ser aquilo que pretendemos professar teoricamente; mas nada nos pode convencer de que somos, a não ser o próprio esforço que fazemos para sê-lo. Esse esforço realiza nosso saber diante de nós mesmos, e esse se torna, justamente por isso, puro produto de nossa liberdade (SCHELLING, 1980, p. 18).
} 
experiência sui generis, que é ao mesmo tempo uma intuição intelectual, capaz de conciliar todas as etapas do conhecimento em um único sujeito. Logo será possível concluir que

\begin{abstract}
Essa intuição intelectual se introduz, então, quando deixamos de ser objeto para nós mesmos e quando, retirado em si mesmo, o eu que intui é idêntico ao intuído. Nesse momento da intuição, desaparecem para nós tempo e duração: não somos nós que estamos no tempo, mas o tempo - ou antes, não ele, mas a pura eternidade absoluta que está em nós. (SCHELLING, 1980, p. 24).
\end{abstract}

Os temas mais cascudos da metafísica se resolvem nesse jogo. Tempo, eternidade, finito e infinito se reconciliam no momento em que o intuído é uma coisa só com o que intui.

Também Hegel se ocupou da fundação da ciência, entretanto, para ele Kant e Fichte já haviam empreendido adequadamente esse caminho. Porém, sempre que tentaram demonstrar a experiência da consciência, projetaram-na como um objeto no mundo, fora de si mesma. A tarefa de Hegel consiste em transformar a consciência num objeto autorreferendado, como o espírito que procura a si mesmo. Esse é o ponto mais alto da filosofia. Hegel não vê outra forma de começar esse caminho a não ser com uma fenomenologia da consciência que tem dois momentos “(a) o saber, e (b) a objetividade que, do ponto de vista do saber é negativo" (HEGEL, 1999, §36). Mas o negativo é um momento a ser superado. A consciência imediata, saindo de si realiza uma experiência negativa, como momento da contradição, ocasião em que seu objeto se encontra fora dela, mas que, ao retornar sobre si mesma produz o verdadeiro conhecimento. Consideremos o passo negativo como sendo a experiência, e sua superação o momento absoluto:

Isso que se chama experiência é próprio desse movimento no qual o imediato, o não expressado, ou seja, o abstrato - pertença, pois ao ser sensível ou a simplicidade apenas pensada -, será antes de tudo estranho a si mesmo e depois esta estranheza retorna a si: só no momento do retorno a si o imediato, que passou a ser também ele, propriedade da consciência, é apresentado e exposta na sua realidade e verdade. (HEGEL, 1999, §36).

A fundação da ciência para Hegel é o conteúdo do próprio conhecimento, e tal conteúdo é alcançado na própria consciência.

O esquema transcendental que Kant estabeleceu, e que revelava uma relação entre o sujeito e a representação de um objeto noumenico, encontrou em Fichte uma nova característica. A relação é, portanto, de esforço do $e u$ contra o $n a \tilde{o} o u^{17}$, resultando em uma

${ }^{17}$ Fichte em sua análise da concepção do esforço (streben), que Schulze tinha apresentado na Crítica kantiana, identifica um dogmatismo intrínseco que considera o espírito exterior as suas próprias ações, e essas como um acidente do próprio espírito. O esforço é reapresentado em chave idealista, como atividade que 
Artigo: Kant e o idealismo: a relação do eu penso com a fundação de toda a ciência no pensamento alemão

superação da alteridade. De qualquer modo, o que Fichte buscou, mesmo superando a existência de um objeto estranho, é o outro de si, por isso, ainda não pode ser o começo absoluto do conhecimento para Hegel, que em sua forma mais alta deve buscar a si mesmo. As dificuldades do pensamento kantiano permanecem presentes na estrutura da filosofia de Hegel. A partir do momento em que Kant fechou a porta para o conhecimento do absoluto a tarefa principal que rodeará o novo sistema será de reintroduzir uma reflexão consequente sobre esse incondicionado.

Aqui se pode partir de uma crítica mais articulada referindo-se a Fichte, que não propriamente a Kant. A ciência, que há o que fazer com as coisas no mundo, por isso cheia de conteúdo, não deve partir de uma representação vazia, como é o caso do eu puro, princípio incondicionado.

O interesse da filosofia para Hegel não deve ser, em linha de princípio, o vazio, mas o conteúdo próprio da história que se analisa mediante qualquer coisa que vive ao interno dessa mesma história. $\mathrm{O}$ aparecimento do espírito é esse momento privilegiado e pleno de conteúdo que pode determinar o absoluto, do momento que o objeto da sua procura não é a representação dos objetos externos ou a superação da diferença, mas é ele mesmo a si procurar. O espírito é identificado com a história e com os fatos no mundo, e a procura essencial não é mais de uma realidade estranha a sua própria existência, mas será sempre a procura de si mesmo, como Hegel chega a afirmar: "o espírito é a causa do mundo e no sentido mais preciso de que um sentimento jurídico, ético-religioso é um sentimento e, portanto, uma experiência de tal conteúdo que tem sua raiz e sede no pensamento" (HEGEL, 1995, I§8).

A ideia de sistema como um círculo que começa e termina no ato de pensar é a fundação que Hegel precisa. Ele exprime essa convicção em suas principais obras. Seja na Lógica, na Fenomenologia do espírito ou na Enciclopédia, ela está sempre presente e serve de base para correção do idealismo anterior, como os de Fichte e de Schelling.

Hegel expressa de maneira bastante concisa essa ideia já a partir da introdução da Enciclopédia §15, ao afirmar que "cada uma das partes da filosofia é um Todo filosófico, um círculo que se fecha sobre si mesmo". Com esse ponto de vista se captura a imagem de totalidade que há no círculo, e sua capacidade de romper as barreiras para fundar outras esferas. Assim, a ideia de fundação da ciência estaria posta dentro de si mesma, em que "o 
todo se apresenta como um círculo de círculos, [e] cada um dos quais é um momento necessário" (HEGEL, 1995, I§15).

Estudar apenas a estrutura da mente foi, para Hegel, uma obra digna do gênio de Kant, mas para a verdadeira filosofia a tarefa é mais árdua. Ela deve se ocupar do necessário e da realidade, impondo suas leis e coordenando seu aparecimento, como resultado do ideal. Não existe um interesse filosófico por uma filosofia da mente que não enquadre o conteúdo do mundo. A conclusão consiste que, para Hegel, a consciência não é transcendental, contra Kant e Fichte. O sujeito do Espírito não é mais o eu transcendental, mas sim o indivíduo universal. Em um grande número de atribuições a consciência (Bewusstsein) hegeliana é muito mais aristotélica que kantiana - indicando, a partir daí, que o único objeto do conhecimento é o conhecimento mesmo. Nesse processo o mundo objetivo é apenas um momento negativo a ser superado no processo do conhecimento; e o que para Kant permanecia indefinidamente fora será agora suprimido no sujeito e na autoconsciência (Selbstbewusstsein).

Hegel está marchando para concluir as questões do eu penso kantiano e dos debates interpostos no desenvolvimento do Idealismo com a compreensão de que "o espírito, que se sabe desenvolvido assim como espírito, é a ciência. A ciência é a efetividade do espírito, o reino que para si mesmo constrói em seu próprio elemento" (HEGEL, 1999, I§25).

Toda a contradição entre o pensamento e o mundo foi removida. A busca por um fundamento da ciência é dissipada na forma de um silogismo do ponto de vista do próprio espírito que pensa a si mesmo, e que pressupõe a natureza fora apenas como um momento lógico. Nele "a ciência aparece como um conhecimento subjetivo que tem por fim a liberdade, e que é, ele próprio, o caminho de produzir-se a liberdade [a si mesma]" (HEGEL, 1995, III§576).

Antes de concluir a sua Enciclopédia com uma homenagem a Aristóteles, citando em original (grego) a famosa passagem da Metafísica XII, 7, na qual Deus é descrito como pensamento de pensamento, Hegel atribuiu ao pensamento humano a mesma característica do pensar divino, cuja ciência é fundada num movimento que "é igualmente atividade do conhecimento, a ideia eterna essente em si mesma e para si, que eternamente se ativa, engendra, e desfruta, como espírito absoluto (HEGEL, 1995, III§577). 
Artigo: Kant e o idealismo: a relação do eu penso com a fundação de toda a ciência no pensamento alemão

\section{CONCLUSÃO}

O Eu penso retomado por Fichte como simplesmente $E u$ que forma o princípio de identidade, evolui em Hegel que se interessa mais por seu caráter absoluto, capaz de exclui a contradição, que propriamente como fundamento da ciência.

A separação que Kant propôs a partir de sua primeira reflexão crítica, de observar a realidade de diversos pontos de vista e com diversos fundamentos, desde que fossem submetidos a uma prévia análise das suas possibilidades, perdeu seu significado mais profundo no idealismo de Fichte e de Hegel, que passaram a investigar novamente o conhecimento e a realidade como qualquer coisa de homogêneo, aos moldes da metafísica absoluta que havia permeado as escolas no alto medievo.

Essa interpretação sucessiva à filosofia de Kant gerou, em larga escala, muito mais dificuldades que propriamente soluções, já que é impossível recorrer a ela sem levar em sérias considerações todo esse aparato de possíveis soluções, estabelecendo um debate contínuo entre kantianos e antikantianos. De Reinhold a Hegel, a filosofia crítica se deteriora e se transforma, como era de se esperar, em múltiplas e variadas vertentes, até se transformas em outra coisa daquilo que o próprio Kant desejava, com a incursão dos neokantianos. Resta, porém, fora de dúvidas, que o criticismo possui características fundamentais, entre elas o que o idealismo tentou negar, a realidade de uma classe de objetos que permanecem fora do sujeito no seu estado noumenico.

\section{REFERÊNCIAS}

ARISTÓTELES. Metafísica. V. 2. São Paulo: Loyola, 2002.

BOUTROUX. Émile. La philosophie de Kant. Paris: Vrin, 1968.

DESCARTES, René, Meditaziones de prima philosophia. In Oeuvres, tomo VII, Paris: Vrin, 1996.

FICHTE, Johann. Rezension Aenesidemu. In: Werke, Bd. II, Stuttgart-Bad Canntatt. Günther Holzboog, 1965.

FICHTE, Johann. A doutrina da ciência de 1794. São Paulo: Nova Cultura, 1988.

HARTMANN, Nicolai. Die Philosophie des deutschen Idealismus. Bd. I. Berlin-Leipzig: Walter de Gruyter \& Co, 1923. 
HARTMANN, Nicolai. Nuove vie dell'ontologia. Brescia: La Scuola, 1975.

HEGEL, Georg. Enciclopédia das ciências filosóficas. v. I-III. São Paulo: Loyola, 1995.

HEGEL, Georg. Fé e saber. São Paulo: Hedra, 2007.

HEGEL, Georg. Fenomenologia do espírito. Petrópolis: Vozes, 1999.

HEGEL, Georg. Wissenschaft der Logik. Nürenberg: J. L. Schrag, 1812.

HUME, David. An Enquiry concerning Human Understanding. Oxford: Clarendon Press, 1998.

KANT, Immanuel. Crítica da razão pura. Lisboa: Calouste Gulbenkian, 1994.

LEON, Xavier. Fichte et son temps. Paris: Armando colin,1922.

MARÉCHAL, Joseph. Le Point de départ de la métaphysique: le système idéaliste chez Kant et les postkantiens. Paris: 1947.

MARKET, Oswaldo. Kant e a recepção de sua obra aos alvores do século XX. In: Recepção da Crítica da razão pura. Lisboa: Fundação Calouste Gulbenkian, 1992.

REINHOLD, Karl. Versuch einer neuen Theorie des menschlichen

Vorstellungesvermögen. Prag-Iena: Widtmann-M. Mauke, 1789.

SCHELLING, Friedrich. Cartas filosóficas sobre o dogmatismos e o criticismo. In: Obras escolhidas. São Paulo, Abril Cultural, 1980.

SCHULZE, Ernst. Aenesidemus oder über die Fundament der Herrn Prof. Reinhold zu Iena, gelieferten Elementar-Philosophie nebst einer Verteidigung des Skeptizismus gegen die Anmaßungen der Vernunftkritik 1792. Berlin: Reuther, 1911.

TILLIETE, Xavier. L’Intuition intellectuelle de Kant à Hegel. Paris: Vrin, 1995. 